\title{
Procedimientos a nivel de ganglio impar
}

\author{
C. E. Restrepo-Garces ${ }^{1,2}$, C. M. Gomez Bermudez ${ }^{1,3}$, S. Jaramillo Escobar ${ }^{1,4}$, L. Jazmin Ramirez ${ }^{1,5}$ \\ y J. F. $\operatorname{Vargas}^{1}$
}

${ }^{1}$ Clínica de Alivio del Dolor. Departamento de Cirugía e Imágenes. Hospital Pablo Tobón Uribe. ${ }^{2}$ Unidad de Alivio del Dolor \& Departamento de Anestesiología. Clínica Las Américas. ${ }^{3}$ Unidad de Alivio del Dolor. Clínica Las Américas. ${ }^{4}$ Anestesiología \& Clínica del Dolor. Clínica del Campestre. ${ }^{5}$ Departamento de Oncología, Dolor \& Cuidados Paliativos. Hospital Pablo Tobón Uribe. Medellín. Colombia

Restrepo-Garces CE, Gomez Bermudez CM, Jaramillo Escobar S, Jazmin Ramirez L, Vargas JF. Procedimientos a nivel de ganglio impar. Rev Soc Esp Dolor 2013; 20(3): 150-154.

\section{INTRODUCCIÓN}

La presencia de dolor crónico perineal es un problema común, asociado a gran disfunción en el paciente y siendo un reto complejo para el médico tratante. La aferencia pélvica es compleja puesto que combina vías simpáticas, parasimpáticas y somáticas.

El ganglio impar (GI) es clásicamente identificado como responsable de la aferencia simpática a periné, vulva, escroto, recto distal, vagina distal y uretra distal. Algunos asocian al GI con vías nociceptivas (vía ramicomunicans), sin ser tan claro este concepto.

El dolor mantenido simpáticamente a nivel perineal, es caracterizado por tener descriptores neuróticos y se acompaña frecuentemente de síntomas de "urgencia", traducido esto como tenesmo doloroso. Al ser responsable de esa aferencia simpática, se postula que los pacientes con mejor respuesta son los que exhiben dichos síntomas neuropaticos.

Desde 1990 se han realizado procedimientos en el GI para el manejo del dolor pélvico-perineal, inicialmente en pacientes con dolor de origen maligno y posteriormente en condiciones benignas, siendo por ejemplo parte integral del algoritmo en el manejo de la coccigodinia.
Los procedimientos a nivel del ganglio impar incluyen, bloqueo con anestésico local, neurolisis (inyección de alcohol o fenol, en dolor maligno), crioterapia y radiofrecuencia térmica. Asimismo también ha sido descrito el empleo de toxina botulínica.

\section{INDICACIONES Y CONTRAINDICACIONES}

Las indicaciones pueden ser divididas en benignas y malignas. Aunque las malignas fueron las que inicialmente fueron reportadas, su empleo en dolor crónico benigno es el más frecuentemente realizado (Tabla I).

Incluyen coccigodinia, dolor perineal idiopático, tenesmo doloroso, proctalgia fugax, vulvodinia, dolor asociado al zoster, dolor crónico posquirúrgico/postraumático (incluyendo recto fantasma), hiperhidrosis, prostatitis crónica y dolor asociado a trombosis hemorroidal.

De las patologías benignas en las que más se han empleado los procedimientos de GI, la coccigodinia es la más frecuente. El empleo de inyección con anestésico local a nivel impar y radiofrecuencia si la respuesta es

TABLA I. INDICACIONES BLOQUEO GANGLIO IMPAR (FRECUENTES)

Coccigodinia

Proctalgia fugax

Proctitis actínica

Vulvodinia

Dolor crónico posquirúrgico

Dolor neuropático perineal (Incluyendo dolor asociado

a zoster)

Dolor maligno perineal 
positiva pero corta, es descrito en algoritmos intervencionistas.

Las causas de dolor maligno involucran malignidad de los órganos pélvicos con extensión a periné, incluyendo cáncer de recto, útero, endometrio, cuello uterino y vejiga; así como el que es producido por lesiones metástasicas. La proctitis actínica y el mismo dolor crónico posquirúrgico pueden ser clasificados como causas de dolor perineal en el sobreviviente de cáncer.

Se debe destacar que la eficiencia en términos de reducción del dolor en pacientes con dolor oncológico es mayor al $60 \%$, siendo el dolor somático "residual" el generador frecuente del síntoma.

Además de su papel terapéutico, el bloqueo del ganglio impar con anestésicos locales debe ser visto también como parte del algoritmo diagnóstico de pacientes con dolor pélvico.

Como en múltiples intervenciones invasivas en dolor se carece de trabajos aleatorios controlados y randomizados o de metanálisis con adecuado número de pacientes, para poder predecir el éxito del procedimiento.

Las contraindicaciones incluyen coagulopatía, infección local o intrabdominal (pélvica), desconocimiento de la técnica e incapacidad de obtener consentimiento informado. Se considera como contraindicación relativa la invasión tumoral al sacro.

\section{ANATOMÍA}

El GI es una estructura solitaria localizada retroperitoneal, sirviendo de terminación a las cadenas simpáticas paravertebrales. Su forma puede ser oval, irregular, triangular, elongada, rectangular o con forma en U. Está posicionado a nivel presacro y su localización tiende a ser variable.

Originalmente fue descrito anterior a la articulación sacro-coccígea, pero puede estar entre este nivel y un punto medio de la punta distal del cóccix. La distancia promedio desde la articulación sacro-coccígea es de $8,6 \mathrm{~mm}$ y desde la punta del cóccix es de $25 \mathrm{~mm}$.

En disecciones anatómicas, las ramas ventrales de los nervios sacros tienden a estar cerca del ganglio impar, lo cual tiene implicaciones para el uso de sustancias neuroliticas y el subsecuente riesgo de neuritis asociadas a las mismas. Esto se traduce en que el volumen final de la sustancia neurolitica (alcohol o fenol) debe ser lo más dirigido para disminuir este riesgo.

\section{DESCRIPCIÓN DE LA TÉCNICA}

Existen reportados 4 aproximaciones básicas al ganglio impar.

1. Ano-coccígea: por línea media o paramediana.

2. Trans-sacrococcígea.
3. Coccígeo-coccígea (también denominada intercoccigea).

4. Lateral (se encuentra referida como paracoccígea, "corkscrew").

Es de notar que en todas está descrito el uso de imagen. No hay lugar para la realización de técnicas a ciegas. Está descrito el empleo de fluoroscopio, ultrasonido y tomografía computarizada (TC).

La descripción original de Plancarte emplea el abordaje a través del plano ano-coccígeo, empleando una aguja angulada para situar la punta en frente de la articulación sacro-coccígea.

Es necesaria la mano no dominante del operador a nivel del recto para evitar perforaciones. Su uso es limitado por riesgos relacionados con la perforación rectal, trauma al operador, la fragmentación de la aguja, la inyección interósea, la incomodidad para el paciente y su fallo que puede alcanzar el $30 \%$. Se ha descrito más recientemente, el empleo de una aguja curva para disminuir los problemas relacionados con el trauma tisular y la fragmentación de la aguja angulada.

La vía intercoccígea es propuesta como una alternativa para pacientes con fusión de la articulación sacro-coccígea. Los autores además afirman que esta ruta facilitaría la dispersión cefálica del inyectado y la visualización lateral puesto que no hay interferencia de los cuernos del primer hueso coccígeo.

Las técnicas paramedianas o laterales son técnicamente más complejas de realizar, pero son alternativas cuando no se puede navegar a través de la unión sacro-coccígea o vía intercoccigea.

Es de suma importancia en pacientes con dolor maligno un estudio detallado de las imágenes disponibles por la posible extensión/infiltración de la lesión al sacro y cóccix, lo que puede impedir la realización del procedimiento.

Las técnicas ecodirigidas (ultrasonido) son cada vez más empleadas en procedimientos intervencionistas en dolor y en este sentido a nivel del GI facilitan la identificación de la unión sacro-coccígea, pero no permite evaluar la dispersión del inyectado, siendo esto más relevante cuando se emplean sustancias neuroliticas.

Todas las descripciones han empleado una aguja o procedimientos de aguja-tras-aguja (needle-trough-needle). De las aproximaciones descritas la más simple y empleada es la trans-sacrococcígea (Tabla II) la cual describimos a continuación:

1. Es necesario que el paciente firme el consentimiento informado, que debe incluir la presencia de efectos secundarios y las posibles complicaciones existentes. Posteriormente se deberá obtener un acceso venoso periférico y el paciente deberá ser monitorizado con ECG, $\mathrm{SaO}_{2}$ y presión arterial no invasiva. Se debe disponer además del equipo necesario para reanimación cardio-cerebro-pulmo- 
TABLA II. PROTOCOLO GENERAL PARA PROCEDIMIENTOS EN GANGLIO IMPAR (SACRO-COCCÍGEO)

1. Documentar consentimiento informado

2. Canalizar acceso venoso periférico

3. En AP localización de la línea media y su relación con la articulación sacro-coccígea

4. Asepsia de manera regular

5. Sedación titulada (considérela en casos oncológicos)

6. Aplicación de anestésico local

7. Introducción de aguja guía. Introducción en lateral de aguja 22 G espinal

8. En lateral avance de la aguja con fluoroscopia intermitente hasta ubicar la punta de la misma anterior a la unión sacro-coccígea

9. Aplicación de medio de contraste en tiempo real vía extensión de anestesia

10. Después de excluir inyección iv o neural, se pueden aplicar $5 \mathrm{ml}$ de inyectado (anestésico local o solución neurolitica)

11. Para procedimientos de radiofrecuencia realizar hasta el paso 9 de manera idéntica con aguja RFK 20 G, 4 lesiones a las $0 \mathrm{hr}, 3 \mathrm{hr}, 6 \mathrm{hr}$ y $9 \mathrm{hr}$

12. Al emplear soluciones neuroliticas "lavar" la aguja con anestésico local o aire para evitar fistulización

13. Retirar la aguja, trasladar a UCPA y dar instrucciones

nar. No es necesaria la aplicación de antibiótico profiláctico.

2. Dependiendo del paciente se podrá emplear analgesia titulada y sedación. Esto puede ser más relevante en pacientes oncológicos para poder tolerar la posición de manera más fácil.

3. El paciente es posicionado en decúbito prono sobre la mesa radio-lúcida, pudiendo emplearse una almohada en el abdomen para eliminar la lordosis y otra para producir ligera flexión de las piernas del paciente con rotación interna para producir una relajación en la pelvis del paciente. Se puede separar de manera ligera la línea media para permitir un acceso a la articulación sacro-coccígea con menos resistencia.

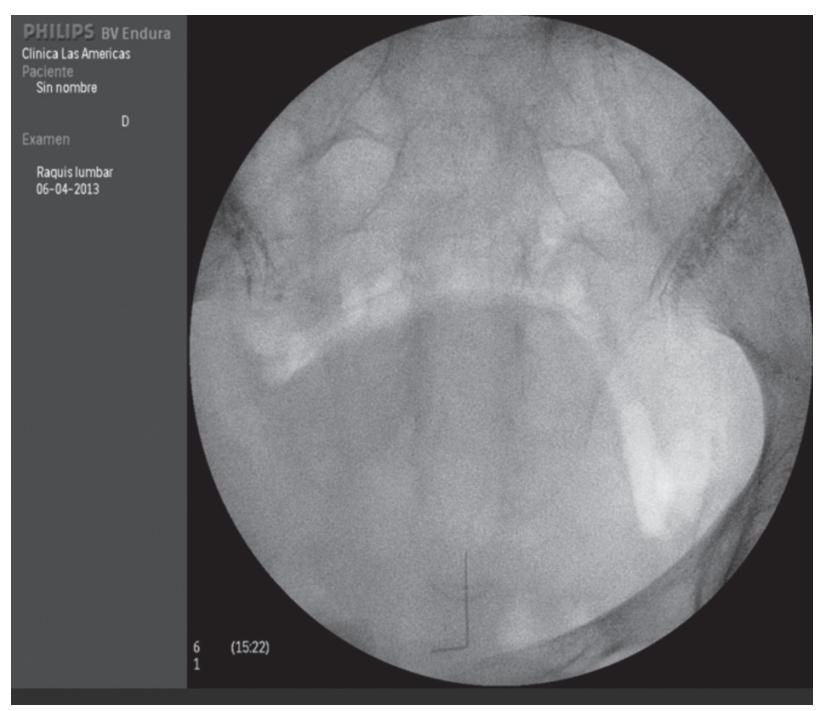

Fig. 1.
4. Esterilización del campo quirúrgico de manera regular.

5. Se identifica inicialmente en AP la línea media y la articulación sacro-coccígea. Esta modificación previa a la evaluación en lateral del blanco evita que la aguja esté en línea media y el inyectado se situé de manera simétrica. Se puede dejar una aguja 21 Gauge hipodérmica como marca. (Fig. 1).

6. Se administra anestésico local (aguja hipodérmica 26 Gauge) lidocaína $1 \%$ ) en piel y tejido celular subcutáneo encima del blanco.

7. La visión es cambiada a lateral, identificando la unión sacro-coccígea, retirando la aguja marca e introduciendo una aguja espinal. La aguja más empleada es 22 Gauge, puesto que permite atravesar la unión sacro-coccígea. Dependiendo del hábito corporal se puede emplear una aguja de 8 o $12 \mathrm{~cm}$. La aguja es avanzada con fluoroscopica intermitente hasta que la punta de la misma se ubique anterior a la unión sacro-coccígea.

8. Se recomienda emplear una extensión de anestesia para evitar movimientos involuntarios anteriores de la aguja. Se aplican de 1 a $3 \mathrm{ml}$ de medio de contraste. El patrón presacro es definido como "el signo de la coma" y al realizar la confirmación en AP se observa una imagen redondeada a nivel de la unión sacro-coccígea. La inyección debe ser realizada en tiempo real para descartar inyección intravenosa. Asimismo el contraste permite evitar inyección neural inadvertida de las raíces sacras (Figs. 2 y 3 ).

9. Los volúmenes de anestésico local o de solución neurolítica han sido descritos entre 1 y $5 \mathrm{ml}$. En pacientes con dolor maligno no se justifica realizar un bloqueo diagnóstico inicial con anestésico local 


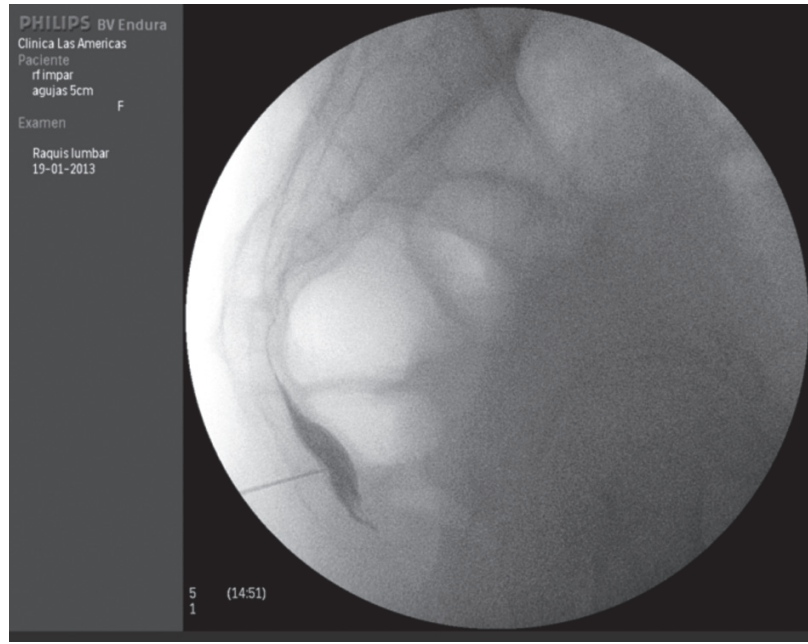

Fig. 2.

y posteriormente en otro procedimiento la inyección del alcohol o el fenol. Es claro que si se emplea alcohol como solución neurolítica se debe aplicar anestésico local previamente. Aunque clásicamente se atribuye al alcohol una duración de acción mayor que el fenol, no existe ningún estudio cabeza-cabeza comparando las dos técnicas. En nuestro centro empleamos fenol al $10 \%$ mezclado con medio de contraste, lo que genera mayor seguridad al poder seguir el inyectado neurolitico.

10. No existe información que respalde el empleo de esteroides durante el procedimiento.

11. En pacientes en los cuales se realizan procedimientos de radiofrecuencia o crioterapia, si es muy útil tener un bloqueo previo diagnóstico-pronóstico con anestésicos locales. La más empleada es la primera con cánulas RFK de 10-15 cm dependiendo del hábito corporal. Las puntas activas de $5 \mathrm{~mm}$ son suficientes. La mayor parte de veces agujas de 20 Gauge son empleadas. Se debe rotar la aguja para obtener una mejor cobertura. En nuestra institución para este fin realizamos lesiones a las 0 horas, 3 horas, 6 horas y 9 horas. No hay reportes hasta el momento de radiofrecuencia fría (cooled RF) o radiofrecuencia bipolar. Se debe tener en cuenta que al realizar la radiofrecuencia convencional se debe aplicar previamente anestésico local el cual puede incrementar el tamaño de la lesión.

12. Al aplicar soluciones neuroliticas es recomendables "lavar" la aguja con anestésico local o con aire para evitar la fistulización del agente neurolitico.

13. Al retirar la aguja el paciente es trasladado a recuperación y son dadas las respectivas instrucciones, incluyendo diario de dolor en los casos de bloqueo diagnóstico.

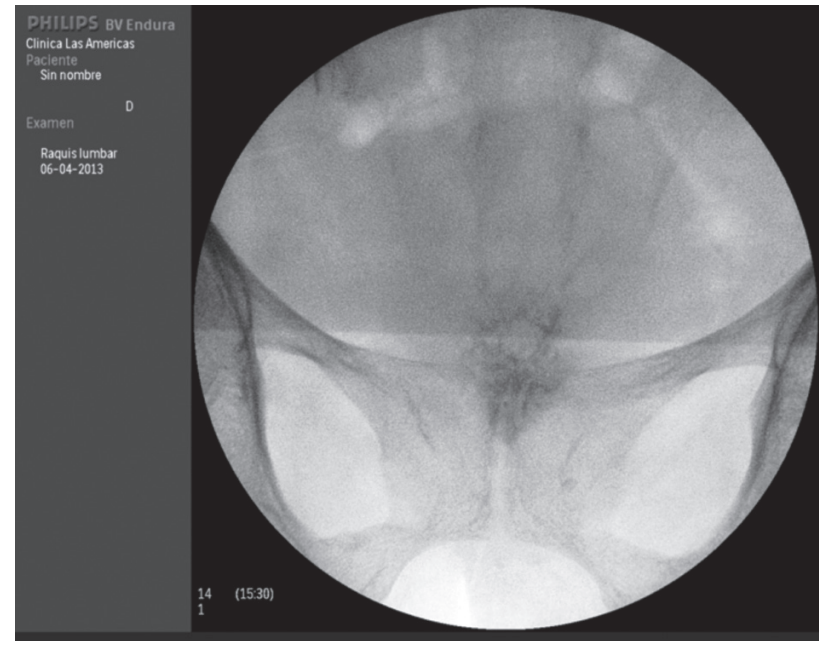

Fig. 3.

\section{COMPLICACIONES Y EFECTOS SECUNDARIOS}

Es un procedimiento con un record de seguridad envidiable, puesto que por el momento no se reportan eventos mortales y/o son mínimos los de morbilidad mayor asociados a la técnica. Por lo reciente de la técnica no existe de manera clara una incidencia de la misma.

Las complicaciones puede ser divididas como las relacionadas con el instrumento (lesiones asociadas la aguja que incluirían fragmentación de la aguja, la punción rectal entre otras), las asociadas a soluciones neurolíticas (neuritis y fistulización del agente neurolitico) y las misceláneas (infección tisular, hematoma, inyección intraósea en la técnica ano-coccígea).

\section{PUNTOS DE INTERÉS Y RECOMENDACIONES PRÁCTICAS}

1. La técnica, como se mencionó al principio, siempre ha tenido el empleo de la imagen como guía, mandatorio para la realización del procedimiento con el objetivo de disminuir complicaciones y aumentar el éxito. Las técnicas aparte de la fluoroscopia incluyen el empleo de TC y ultrasonido. El empleo de la TC es alternativa en pacientes con anatomía alterada y teóricamente disminuiría las complicaciones intrapélvicas asociadas a trauma con la aguja. El ultrasonido tiene la ventaja de ser una herramienta móvil que puede ser llevada hasta el paciente, pero como se comentó previamente, aún no se puede hacer una recomendación formal en términos de seguimiento del inyectado, especialmente si se emplean sustancias neurolíticas.

2. Las técnicas paramedianas son interesantes en la medida de no involucrar la unión sacro-coccígea ni 
la intercoccígea. Asimismo no necesitan la manipulación rectal digital como la vía ano-coccígea. Las agujas deben ser anguladas 20 a 30 grados para poder navegar. Se ha recomendado una maniobra "corkscrew" (sacacorcho) para acceder al blanco. En AP la aguja es dirigida lateral e inferior a la unión sacrococcígea, inferior a la unión del proceso transverso y el cuerpo del cóccix. Al realizar contacto óseo, la aguja es rotada y avanzada suavemente hasta cabalgar el cuerpo coccígeo. Una vista lateral debe situar la aguja en el tercio posterior del cuerpo, en ese instante la aguja es rotada caudalmente y medial hasta estar anterior en el espacio presacro.

3. Al realizar procedimientos de radiofrecuencia la estimulación motora es deseable para descartar compromiso radicular sacro.

4. No hay evidencia de superioridad o de indicación clara de técnicas de radiofrecuencia pulsada sobre radiofrecuencia convencional térmica.

5. Aunque no hay fundamento para emplear esteroides en la inyección con anestésico local, muchos practicantes lo emplean después de lesiones de radiofrecuencia para disminuir posible neuritis.

6. La evidencia existente hasta la fecha puede graduarse como evidencia $1 \mathrm{C}$.

\section{CORRESPONDENCIA}

Director, Unidad de Alivio del Dolor Departamento de Anestesiología, Clínica Las Américas, Medellin, Colombia

Carrera 80 2A 80-140, Torre Medica, Consultorio 303

Tel: (574) 3459131

Fax: (574) 3459132

e-mail: carlosedo75@gmail.com

\section{BIBLIOGRAFÍA}

1. Scott-Warren JT, Hill V, Rajasekaran A. Ganglion Impar Blockade: A Review. Curr Pain Headache Rep. 2013;17:306. Doi 10.1007/s11916-012-0306-7.

2. Oh CS, Chung IH, Ji HJ, et al. Clinical implications of topographic anatomy on the ganglion impar. Anesthesiology. 2004;101:249-50.

3. de Leon-Casasola OA. Superior hypogastric plexus block and ganglion impar neurolysis for pain associated with cancer. Tech Reg Anesth Pain Manag. 1997;1:27-31.

4. Wemm JR K, Saberski L. Modified approach to block the ganglion impar (ganglion of Walther) (letter). Reg Anesth. 1995;20:544-5.

5. Plancarte R, Amescua C, Patt RB, et al. Presacral blockade of the Ganglion of Walther (Ganglion Impar). Anesthesiology. 1990;73:A751.

6. Toshniwal GR, Dureja GP, Prashanth SM. Transsacrococcygeal approach to ganglion impar block for management of chronic perineal pain: a prospective observational study. Pain Physician. 2007;10:661-6.

7. Vranken JH, Bannink IMJ, Zuurmond WWA. Invasive procedures in patients with coccygodynia: caudal epidural infiltration, puden- dal nerve block, and blockade of the ganglion impar. Reg Anesth Pain Med. 2000;25:25.

8. Patijn J, Janssen M, Hayek S, et al. Coccygodynia. Pain Pract. 2010;10:554-9.

9. Lim SJ, Park HJ, Lee SH, et al. Ganglion impar block with botulinum toxin type A for chronic perineal pain: a case report. Korean J Pain. 2010;23:65-9.

10. Datir A, Connell D. CT-guided injection for ganglion impar blockade: a radiological approach to the management of coccygodynia. Clin Radiol. 2010;65:21-5.

11. Foye PM, Patel SI. Paracoccygeal corkscrew approach to ganglion impar injections for tailbone pain. Pain Practice. 2009;9:317-21. 